\title{
Observations on autoimmune orchitis in sterile mice carrying a recessive lethal mutation at the $T / t$ complex exhibiting spontaneous allergic orchitis
}

\author{
G. B. Dooher, Karen Artzt, Dorothea Bennett and Ursula Hurtenbach* \\ Sloan-Kettering Institute for Cancer Research, Laboratory of Developmental Genetics, \\ New York, New York 10021, U.S.A.
}

\begin{abstract}
Summary. Electron microscopic observations of testes of sterile, backcross $T / t^{\mathbf{w} 18}$ mice which spontaneously develop allergic orchitis have demonstrated accumulations of lymphocytes and occasional plasma cells between seminiferous tubules in affected mice. Many lymphocytes appeared to be insinuated amongst cytoplasmic processes of the peritubular adventitial cells which, in most samples, provided a barrier to direct infiltration of the germinal epithelium by lymphocytes. Although lymphocytes were rarely observed within the seminiferous epithelium, extensive degeneration of spermatogenic cells was observed within affected tubules. Sertoli cells phagocytosed degenerating germ cells at all stages of differentiation. In-vitro co-cultivation of syngeneic $T / t^{\text {w18 }}$ spleen and testicular cells revealed that testicular cells from sterile $T / t^{\mathrm{w18}}$ mice failed to activate suppressor $T$ lymphocytes; consequently, the syngeneic splenocytes displayed a vigorous proliferative response to testicular autoantigens. Testicular cells from younger, fertile $T / t^{\mathbf{w 1 8}}$ males, on the other hand, behaved like testicular cells from normal mice, triggering suppressor $\mathrm{T}$ cell activity and, thereby, abrogating proliferation of splenocytes. These results suggest genetic factors, introduced in the course of inbreeding and associated with chromosome 17, are responsible for the failure of spermatogenic cells from sterile $T / t^{\mathrm{w} 18}$ males to maintain normal tolerance to their own antigens in vivo; allergic orchitis is an extreme manifestation of the inability of the defective germ cells to initiate normal $\mathrm{T}$ lymphocyte mediated suppression of an immune response.
\end{abstract}

\section{Introduction}

The autoimmunogenicity of mammalian spermatogenic cells has been well demonstrated (Tung, 1977); survival of the male germ line in the seminiferous epithelium appears to depend in part upon the integrity of the blood-testis barrier, behind which spermatogenic cells display unique differentiation antigens which normally remain undetected by the organism's immune system (Johnson, 1973). There is evidence, however, that certain autoantigens present on spermatogenic cells probably do gain access to the immune system; naturally occurring antibodies reactive with germ cell-specific antigens circulate in the plasma of many individuals who nevertheless show no signs of impaired reproductive function (Koo, Boyse \& Wachtel, 1977; Tung, 1977). Moreover, immunological responsiveness to the male germ line can be induced experimentally by immunization with germ cells or antigenic extracts obtained from them in complete Freund's

* Present address: Immunology Branch, National Institutes of Health, Bethesda, Maryland 20205, U.S.A. 
adjuvant, which leads in some species to antibody production followed by $\mathrm{T}$ lymphocytedependent destruction of the seminiferous epithelium, a phenomenon referred to as experimental allergic orchitis (Tung, Unanue \& Dixon, 1971). Maintenance of normal spermatogenesis therefore appears to depend not only upon the sequestered environment of the germ cells but also upon the existence of a balance between immunological responsiveness and circulating germ cell antigens (Tung, 1980).

Normal spermatogenic cells can activate suppressor $\mathrm{T}$ cells in vitro; and as a consequence lymphocyte proliferation in vitro against autologous testicular cells or allogeneic spleen cells is curtailed (Hurtenbach, Morgenstern \& Bennett, 1980). This phenomenon may reflect mechanisms prevailing in vivo by which spermatogenesis proceeds normally in spite of the antigenicity of the cells and the leakiness of the blood-testis barrier.

Allergic orchitis is not confined to experimental animals but occurs spontaneously in some genetically uniform strains of laboratory animals, e.g. A-line beagles (Fritz, Lombard, Tyler \& Norris, 1976). Although genetic factors presumably play a role in susceptibility to experimentally induced and naturally occurring orchitis, the basis for these phenomena remains largely unknown. We have been studying a form of allergic orchitis which arises spontaneously in a congenic strain of mice in our laboratory and in this report we provide morphological observations on the course of the disease and data relating to the immunological basis for this disorder.

\section{Materials and Methods}

Mice

The mice that develop allergic orchitis originated in this laboratory; we were attempting to place a recessive lethal $t$-haplotype $\left(t^{\mathrm{w1}}\right)$ on an inbred genetic background (BTBRTF/Nev) that carried the dominant mutation Brachyury $(T)$. To produce this congenic line we backcrossed heterozygotes for the recessive allele (genotype $+/ t^{\mathrm{w18}}$ or $T / t^{\mathrm{w18}}$ ) to the inbred mice that carry the dominant mutation (genotype $T /+$ ). Embryos of five possible genotypes arise from such crosses: $T / T ; T /+; T / t^{\mathrm{w18}} ;+/ t^{\mathrm{w18}}$; and $+/+. T / T$ embryos die at about $10 \cdot 5$ days of gestation; $T /+$ mice are recognized on the basis of a short-tailed phenotype; $T / t^{\mathbf{w 1 8}}$ animals are tailless. The phenotypes of $+/ t^{\mathrm{w18}}$ and $+/+$ mice are identical; the presence of $t^{\mathrm{w18}}$ must be determined by progeny testing.

Before 1969 the parental $t^{\mathrm{w18}}$ stock was maintained simultaneously at the Nevis Biological Station of Columbia University and at Cornell University Medical College, both in closed colonies which also segregated for $T$. The stock was outcrossed in 1969 to the inbred BALB T line which carries a dominant lethal mutation $T^{\mathrm{J}}$ indistinguishable from $T$. This outcross was an attempt to renew the reproductive vigour of the original $T / t^{\mathrm{w18}}$ stock, which already showed signs of reduced fecundity, probably due to inbreeding. Thus $T^{\mathrm{J}} / t^{\mathrm{w18}}$ animals were employed initially to introduce $t^{\mathrm{w} 18}$ into the BTBRTF/Nev genetic background.

The essential point is that after about the 5th backcross generation, almost all tailless male mice $\left(T / t^{\mathrm{w18}}\right)$ and the great majority of female tailless animals proved to be completely sterile, whereas more than $60 \%$ of normal tailed mice showed normal fertility (see Table 1 for data summary). We began morphological studies when the stock was in backcross 5-6; sampling continued through to the 12th backcross generation. Mice ranged from 3-14 months of age when killed. The present study was undertaken to determine the reason for the widespread infertility exhibited by $T / t^{\mathrm{w1}}$-bearing males.

\section{Structural observations}

Mice were killed by cervical dislocation. The testes were removed and processed for light and electron microscopy. Sections of Bouin-fixed, paraffin wax-embedded testes were stained with 
Table 1. Results of breeding tests of $T /+$ mice $\left(\mathrm{F}_{26}-\mathrm{F}_{33}\right)$ of normal fertility and of backcross segregants for $t^{\mathrm{w18}}(\mathrm{BC} 5-23)$

\begin{tabular}{|c|c|c|c|c|c|}
\hline & \multicolumn{5}{|c|}{ Genotype } \\
\hline & $T /+$ & $T / t^{\mathbf{w 1 8}}$ & $+/ t^{\mathrm{w18}}$ & $+/+$ & $+/ ?$ \\
\hline \multicolumn{6}{|l|}{ Males } \\
\hline No. fertile/no. sterile & $25 / 3$ & $3 / 45$ & $26 / 0$ & $34 / 0$ & $0 / 48$ \\
\hline$\%$ Fertile & 89 & 6 & 100 & 100 & 0 \\
\hline \multicolumn{6}{|l|}{ Females } \\
\hline No. fertile/no. sterile & $15 / 1$ & $8 / 48$ & $32 / 0$ & $33 / 0$ & $4 / 20$ \\
\hline$\%$ Fertile & 94 & 14 & 100 & 100 & 17 \\
\hline
\end{tabular}

haematoxylin and eosin for light microscopy. Tissues for electron microscopy were fixed in glutaraldehyde and osmium tetroxide and processed as previously described (Dooher \& Bennett, 1973); araldite was used for embedding.

\section{In-vitro studies}

Preparation of the cell suspensions and the culture conditions have been described previously (Hurtenbach et al., 1980). Briefly, $5 \times 10^{5}$ spleen cells, used as responders, were cultivated in flat-bottomed microtitre plates (Fisher Scientific, Springfield, New Jersey) with $5 \times 10^{5}$ irradiated (2000 rads) splenic stimulators or with $2 \times 10^{5}$ testicular cells in a total volume of 200 $\mu \mathrm{l}$. The testicular cells were obtained from the seminiferous tubules by protease treatment. After removal of the capsule the testes were incubated at $37^{\circ} \mathrm{C}$ for $12 \mathrm{~min}$ in $0.1 \%$ collagenase (Worthington Biochemical Co., Massachusetts), dissolved in phosphate-buffered saline (PBS), $\mathrm{pH}$ 7.2. The seminiferous tubules, mostly freed of interstitial cells and connective tissue elements, were then broken up by a 15 -min incubation at $37^{\circ} \mathrm{C}$ in $0.025 \%$ trypsin (GIBCO, Grand Island, New York) dissolved in $\mathrm{Ca}^{2+}$ - and $\mathrm{Mg}^{2+}$ - free PBS. This treatment released germ cells and Sertoli cells; this cell population enriched for germ cells was designated as of Te cells. For cultivation the single cell suspensions were resuspended in RPMI 1640 (GIBCO) supplemented with $1 \%$ normal mouse serum plus $0.05 \mathrm{~mm}$-2-mercaptoethanol. The mouse serum was obtained from young adult donors, syngeneic to the responder population, and heat-inactivated $\left(30 \mathrm{~min}, 56^{\circ} \mathrm{C}\right)$ before use. After 4 days of cultivation in a humidified atmosphere of $7 \% \mathrm{CO}_{2}$ in air in a $37^{\circ} \mathrm{C}$ incubator, $20 \mu \mathrm{l}\left[{ }^{3} \mathrm{H}\right]$ thymidine solution $(50 \mu \mathrm{Ci} / \mathrm{ml} ; 0.5$ $\mathrm{mm}$ unlabelled thymidine in PBS) were added; $16 \mathrm{~h}$ later the labelled cultures were harvested and the radioactivity was determined in a liquid scintillation counter. Mean values and standard deviation were estimated from 5 replicate cultures. Stimulation index was calculated from the formula: c.p.m. experimental/c.p.m. background.

\section{Results}

\section{Structural observations}

Light microscopy. Of 20 sterile $T / t^{\mathrm{w18}}$ males, $12(60 \%)$ had testes of normal histological appearance while the other 8 showed clear indications of lymphocyte-mediated inflammatory reactions in one or usually both testes. As negative controls 8 congenic $T /+$ and 6 normal tailed (genotype $+/ t^{\mathrm{w1} 18}$ ) animals were selected and examined histologically. None of the 14 control males exhibited signs of allergic orchitis. 
Examination of sections of paraffin-wax and plastic embedded seminiferous tubules by light microscopy revealed that affected testes contained occasional clusters of mononuclear cells scattered between seminiferous tubules (Pl. 1, Figs 1 and 2). In the most severely affected animals, about $20-30 \%$ of tissue observed displayed frank histological evidence of orchitis; in most individuals approximately $10-20 \%$ of tubules were involved. The majority of cells were identified as small to medium-sized lymphocytes on the basis of nuclear morphology and scant, basophilic cytoplasm. Occasionally, plasma cells were also observed. Portions of seminiferous tubules adjacent to aggregates of lymphoid cells usually, but not invariably, appeared abnormal. However, abnormal morphology was restricted to the area with which lymphocytes were associated (Pl. 1, Figs 1 and 2). In affected tubules, germ cells were absent or present in abnormally low numbers and germ cells containing pycnotic nuclei were commonly observed (Pl. 1, Fig. 2).

Electron microscopy. The intertubular tissue of the normal mouse testis contains clusters of Leydig cells, sparse connective tissue elements, small calibre blood vessels and abundant, thin-walled lymphatic capillaries. Occasional lymphocytes and plasma cells are observed. A single layer of adventitial cells intervenes between the seminiferous epithelium and the extratubular space. A basement membrane, consisting of an amorphous lamina and an outer network of collagen fibres, is present on the adluminal and interstitial surface of the adventitial cells.

In testes of animals with orchitis, the normal organization of the interstitial tissue was disrupted locally by numerous lymphocytes and less abundant plasma cells (PI. 1, Fig. 3). Neither macrophages nor granulocytes were detected in association with aggregates of lymphoid cells. Most of the cells appeared to be lodged between tapering processes of the adventitial cells which normally form an uninterrupted barrier between the germinal epithelium and the extratubular space. At these sites of lymphocytic infiltration the adventitial cells frequently exhibited abundant overlapping and complexly interdigitating processes not normally observed (PI. 1, Fig. 3). Although the basement membrane that sheathes the adventitial cells usually persisted in such regions, it frequently had a disorganized appearance, particularly between the layer of adventitial cells and the seminiferous tubules (Pl. 2, Fig. 4). Commonly, several irregular laminae of amorphous material and an unusually extensive feltwork of collagenous fibrils were observed (Pl. 2, Figs 4 and 5). Occasional gaps, several $\mu \mathrm{m}$ in width, were sometimes seen between cytoplasmic processes of the adventitial cells. In these regions, lymphocytes touched the basement membrane of the germinal epithelium itself (Pl. 2, Figs 4 and 5). Frequently, lymphocytes were studded with short surface projections by which adjacent cells appeared to establish contact (Pl. 2, Fig. 5). In addition to numerous short surface projections, lymphocytes also displayed larger, tapering cytoplasmic extensions, particularly at sites between adjacent processes of adventitial cells that may be related to migratory activity (Pl. 2, Fig. 5). Lymphocytes were rarely detected within the germinal epithelium although a few were seen lodged between germ cells and Sertoli cells (Pl. 3, Fig. 6).

Within the seminiferous tubules adjacent to accumulations of lymphocytes, Sertoli cells frequently contained electron-dense lamellar bodies as well as fragments of late spermatid nuclei and flagella (PI. 3, Fig. 7). Inspection by light and electron microscopy revealed no evidence of involvement of somatic macrophages with intratubular phagocytic activity.

\section{Immunological studies in vitro}

Experiments were set up to investigate whether the autoimmune orchitis in sterile $T / t^{\mathrm{w18}}$ males reflected either abnormal immunocompetence or a defect in the ability of germ cells to activate a functionally normal population of suppressor $\mathrm{T}$ lymphocytes. To test both possibilities we compared lymphocyte reactivity of 6-10-week-old $T / t^{\mathrm{w18}}$ males (referred to as fertile) and 5-6-month-old mice (sterile) against allogeneic spleen cells as well as against syngeneic testicular 

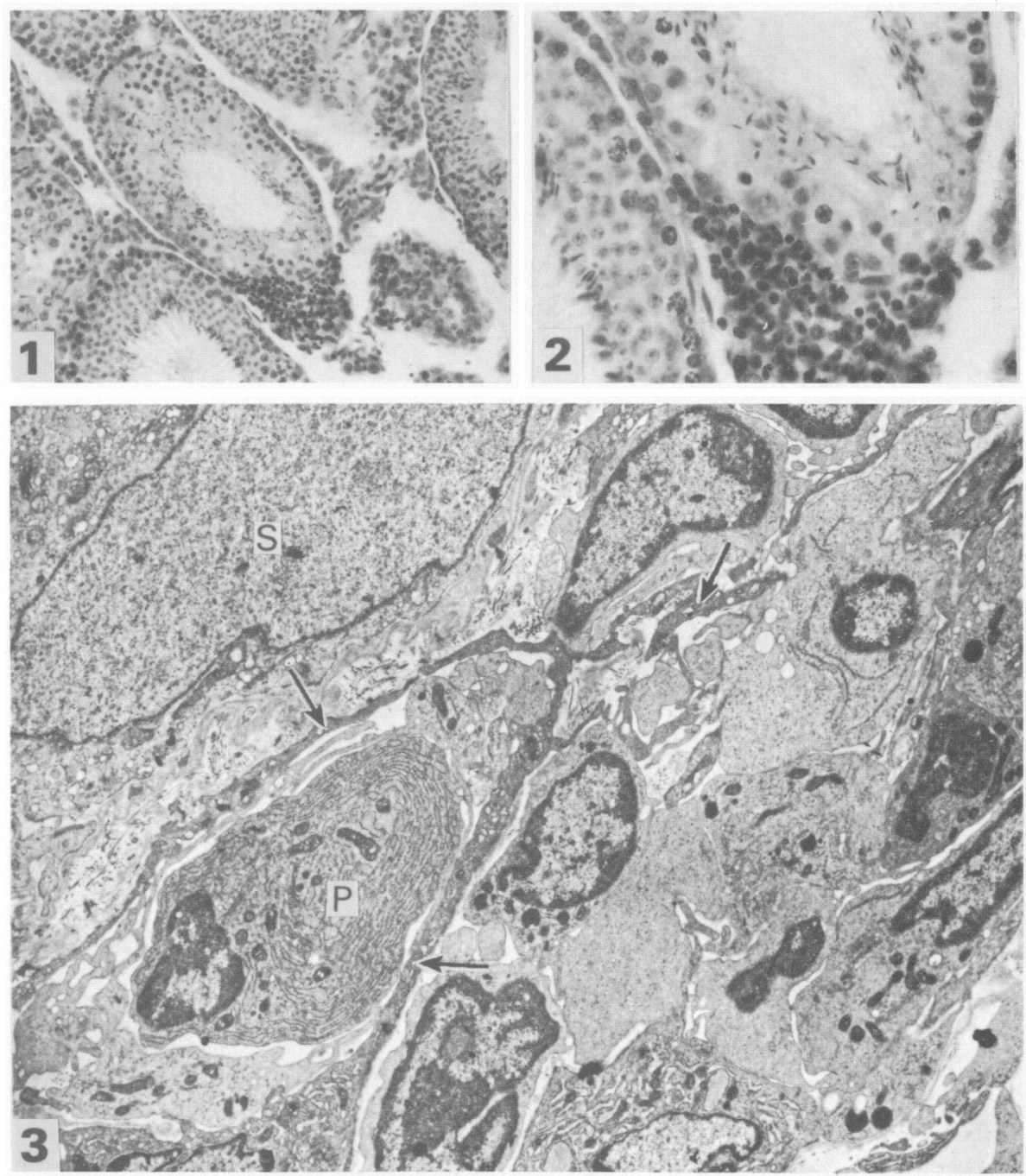

Fig. 1. Low power micrograph illustrating an accumulation of lymphocytes along one side of a seminiferous tubule, the epithelium of which is relatively poor in germ cells. Interstitial tissue and adjacent seminiferous tubules display normal histology. $\times 200$.

Fig. 2. Higher magnification view of a portion of the field included in Fig. 1. Small and medium-sized lymphocytes appear to encroach upon, but not to enter, the seminiferous tubule with which they are associated. Spermatozoa, spermatids and spermatocytes are depleted in numbers; a few densely staining cells probably represent pycnotic germ cells. $\times 400$.

Fig. 3. Electron micrograph of lymphocytes and a plasma cell $(P)$ adjacent to a seminiferous tubule containing a Sertoli cell $(\mathrm{S})$. Many of the lymphocytes are irregular in shape. Numerous densely staining cytoplasmic processes of adventitial cells (arrowed) extend between lymphocytes. $\times 4700$. 
PLATE 2
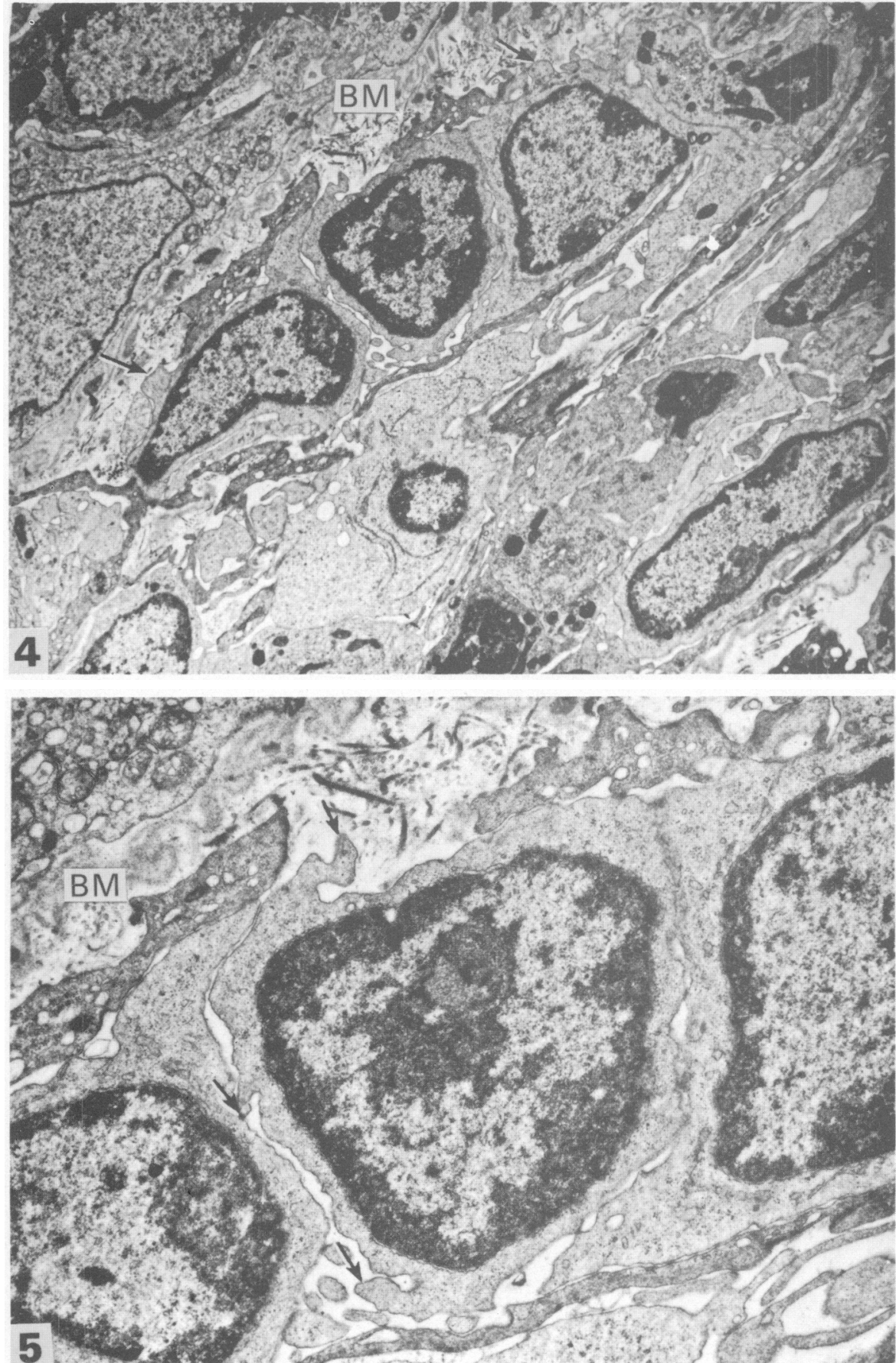

Fig. 4. At regions of accumulations of lymphocytes, the basement membrane (BM) of the seminiferous tubule frequently displays a disorganized appearance including dense lamellae of amorphous material and an extensive network of collagenous fibrils. The layer of adventitial cells shows frequent abnormal interruptions through which lymphocytes protrude (arrowed). $\times 4700$.

Fig. 5. Higher magnification of a portion of the field included in Fig. 4. The disorganized appearance of the basement membrane (BM) is clearly seen. Lymphocytes are studded with projections (arrowed) of variable size. $\times 12900$. 


\section{PLATE 3}
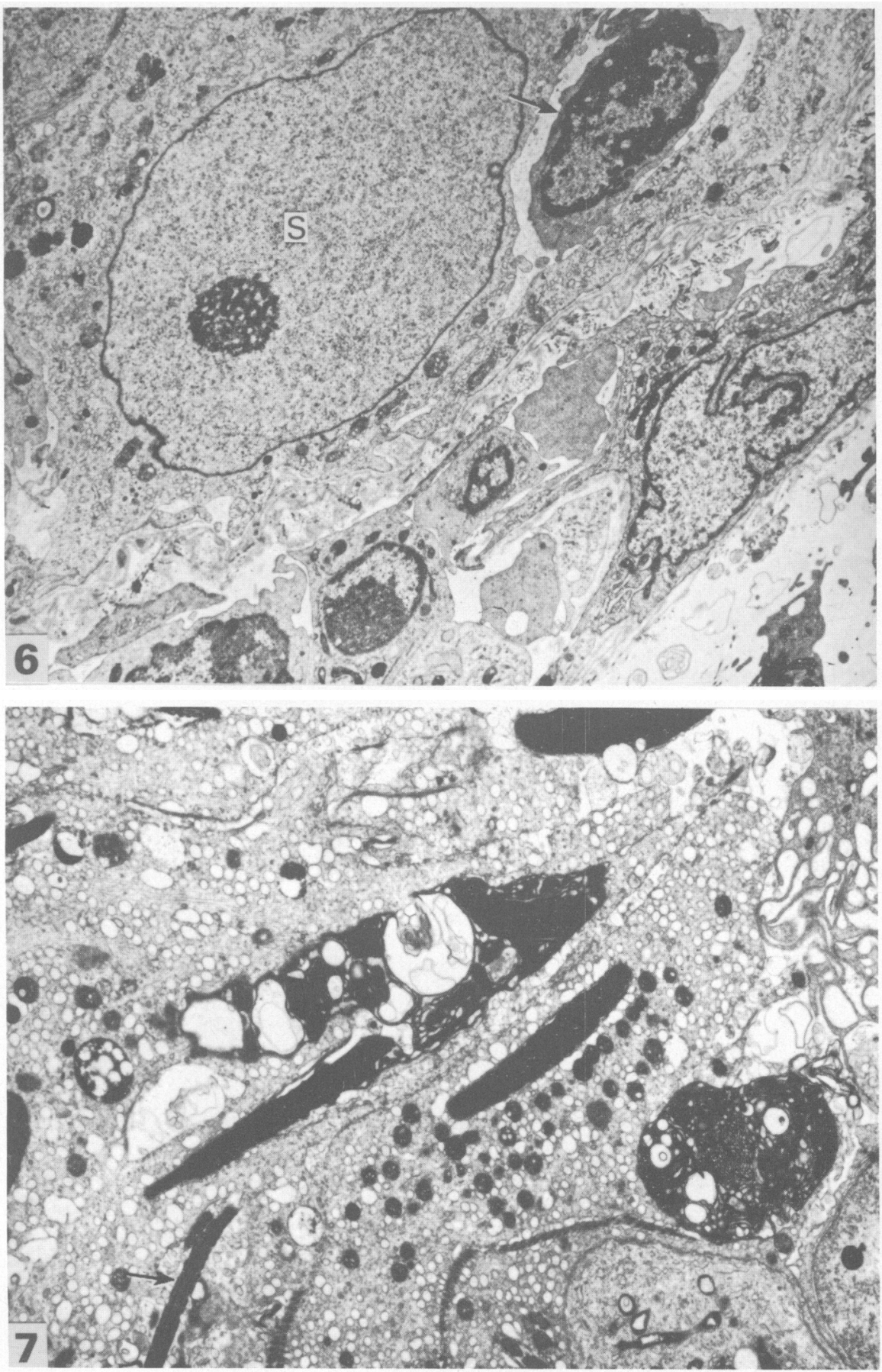

Fig. 6. An example of an intratubular lymphocyte (arrowed) located next to a Sertoli cell (S). $\times 4700$.

Fig. 7. Electron micrograph of Sertoli cell cytoplasm containing phagocytosed fragments of late spermatid nuclei and densely staining lamellar bodies. A sperm tail (arrowed) is also observed embedded in the cytoplasm of a Sertoli cell. $\times 4700$. 
cells from animals of both ages. We selected animals of these two age ranges since occasional $T / t^{\mathrm{w18}}$ males approximately 10 weeks of age showed normal fertility whereas by $5-6$ months of age the $T / t^{\mathrm{w18}}$ mice never bred and, moreover, frequently showed signs of orchitis.

Table 2. Incorporation of $\left[{ }^{3} \mathrm{H}\right]$ thymidine into spleen cells from fertile and sterile $T / t^{\mathbf{w 1 8}}$ mice

\begin{tabular}{|c|c|c|c|c|}
\hline \multirow[b]{2}{*}{ Stimulators } & \multicolumn{2}{|c|}{ Fertile $T / t^{w 18}$ spleen } & \multicolumn{2}{|c|}{ Sterile $T / t^{\mathrm{w} 18}$ spleen } \\
\hline & c.p.m. & $\mathrm{SI}^{*}$ & c.p.m. & $\mathrm{SI}^{*}$ \\
\hline$\phi$ & $768 \pm 19$ & & $597 \pm 113$ & \\
\hline AKR spleen & $5701 \pm 392$ & $7 \cdot 4$ & $5349 \pm 305$ & 8.9 \\
\hline AKR Te cells & $994 \pm 53$ & $1 \cdot 3$ & $695 \pm 192$ & $1 \cdot 2$ \\
\hline $\begin{array}{l}\text { AKR spleen }+ \\
\text { AKR Te cells }\end{array}$ & $1895 \pm 250$ & $2 \cdot 4$ & $2891 \pm 146$ & 4.8 \\
\hline \multicolumn{5}{|l|}{ Fertile } \\
\hline$T / t^{\mathrm{w18}} \mathrm{Te}$ cells & $640 \pm 187$ & 0.8 & $831 \pm 47$ & 1.4 \\
\hline \multicolumn{5}{|l|}{ Sterile } \\
\hline$T / t^{\text {w18 }} \mathrm{Te}$ cells & $5405 \pm 254$ & $7 \cdot 0$ & $5364 \pm 851$ & $10 \cdot 0$ \\
\hline $\begin{array}{l}\text { AKR spleen }+ \text { fertile } \\
T / t^{\text {w18 }} \mathrm{Te} \text { cells }\end{array}$ & $2504 \pm 221$ & $3 \cdot 2$ & $2141 \pm 586$ & $3 \cdot 6$ \\
\hline $\begin{array}{l}\text { AKR spleen + sterile } \\
T / t^{\mathrm{w18}} \mathrm{Te} \text { cells }\end{array}$ & $5373 \pm 93$ & $7 \cdot 0$ & $5094 \pm 291$ & $8 \cdot 5$ \\
\hline
\end{tabular}

Values are mean \pm s.e.m. for one representative of 6 experiments.

* SI = stimulation index.

Table 2 shows that splenocytes from either sterile or fertile $T / t^{\text {w18 }}$ males had entirely comparable and vigorous proliferative responses to allogeneic AKR spleen cells in vivo and were likewise quite similar in showing essentially no reactivity to germ cell-rich Te cell fractions of AKR testicular cells. In accordance with previous results with normal mice, the allogeneic response to AKR splenocytes was reduced significantly when they were co-cultivated with syngeneic Te cells from fertile mice or with Te cells from AJ mice; again sterile and fertile males were indistinguishable. These data suggest that the lymphoid cell populations in sterile $T / t^{\mathbf{w 1 8}}$ males are normal.

Table 2 also reveals, however, that the germ-cell rich Te cell fractions from sterile and fertile $T / t^{\mathrm{w} 18}$ males behaved very differently when used as stimulators. A concentration of $T / t^{\mathrm{w18}} \mathrm{Te}$ cells from fertile mice which had been shown consistently to induce suppression of the proliferative response when derived from normal mice (Hurtenbach et al., 1980) provoked virtually no proliferative response from syngeneic splenocytes of fertile or sterile $T / t^{\mathrm{w18}}$ males. In mixed cultures with AKR spleen cells their presence resulted in severely curtailed allogeneic responses. Under the same conditions, sterile $T / t^{\mathbf{w 1 8}}$ males, however, yielded Te cells which elicited an in-vitro proliferation from both syngeneic spleen cell populations that was comparable to the response induced by allogeneic spleen cells, and furthermore showed no tendency to abrogate the allogeneic response in mixed cultures. It therefore appears that $T / t^{\mathbf{w 1 8}}$ testicular germ cells from sterile mice may be unable to induce suppressor $T$ cells.

In further experiments we tested the effects of Te cells from sterile $T / t^{\mathrm{w1B}}$ males on the proliferation of lymphocytes from congenic, wild type BTBRTF/Nev mice. As Table 3 shows, with a stimulation index of 2 , autologous $\mathrm{Te}$ cells $(+/+)$ as well as $\mathrm{AJ}$ Te cells induced significantly lower lymphocyte reactivity than did the same number of $T / t^{\mathrm{w18}} \mathrm{Te}$ cells from sterile mice $(P<0.01$; stimulation index 5.3). Moreover, Te cells from sterile males apparently also failed to evoke suppression of alloreactivity. These data confirm previous findings that lack of suppression is not due to failure of the responder population, but rather to a failure of the testicular cell population of the sterile $T / t^{\mathrm{w18}}$ mice. 
Table 3. Incorporation of $\left[{ }^{3} \mathrm{H}\right]$ thymidine into spleen cells from wild-type BTBRTF/Nev $(+/+)$ mice against testicular cells from sterile $T / t^{\mathbf{w 1 8}}$ mice

\begin{tabular}{|c|c|c|}
\hline Stimulators & c.p.m. & $\begin{array}{l}\text { Stimulation } \\
\text { index }\end{array}$ \\
\hline$\phi$ & $2084 \pm 197$ & \\
\hline$+1+$ Te cells & $4286+331$ & 2.0 \\
\hline$T / t^{\omega 18} \mathrm{Te}$ cells & $11124 \pm 955$ & $5 \cdot 3$ \\
\hline $\mathrm{A} / \mathrm{J} \mathrm{Te}$ cells & $4917 \pm 421$ & $2 \cdot 3$ \\
\hline $\mathrm{A} / \mathrm{J}$ spleen & $19692 \pm 435$ & 9.4 \\
\hline A $/ \mathrm{J}$ spleen $++1+$ Te cells & $5928 \pm 671$ & $2 \cdot 8$ \\
\hline $\mathrm{A} / \mathrm{J}$ spleen $+T / t^{\text {w18 }} \mathrm{Te}$ cells & $18197+1442$ & 8.7 \\
\hline $\mathrm{A} / \mathrm{J}$ spleen $+\mathrm{A} / \mathrm{J}$ Te cells & $6925 \pm 550$ & $3 \cdot 3$ \\
\hline
\end{tabular}

Values are mean \pm s.e.m. for one representative of 3 experiments.

\section{Discussion}

Although experimentally induced allergic orchitis has been frequently studied in laboratory animals, few descriptions of heritable spontaneous orchitis in laboratory animals have been reported. Spontaneous orchitis has been described in testes of inbred A-line beagles (Fritz et al., 1976). In over $70 \%$ of these animals, testes develop severe lymphocytic infiltration of the interstitial tissue and, occasionally, seminiferous tubules, and concomitant degeneration of the germinal epithelium. This condition closely resembles the pathology reported here for $T / t^{\mathrm{w} 18}$ mice. In a smaller proportion of beagles, most germ cells disappear spontaneously from the seminiferous tubules, a phenomenon we have not observed.

The morphological characteristics of allergic orchitis described here are specific and complex. Adventitial cells and Sertoli cells show morphological changes in affected tubules; the Leydig cells and other cells of the interstitium do not appear to be affected in the immune response. Our observations suggest that the adventitial cells play an important role in maintaining the integrity of the seminiferous epithelium despite large numbers of encroaching lymphocytes. By morphological criteria these cells constitute the first and rarely broached line of defence, an unexpected finding in view of the high permeability of these cells to blood- and tissue-borne macromolecules and the paucity of junctions between the cells (Dym \& Fawcett, 1970). Neither somatic macrophages nor granulocytes are significant members of the inflammatory cell population. In guinea-pigs, on the other hand, experimental allergic orchitis is accompanied frequently by the accumulation and significant infiltration of the seminiferous epithelium by macrophages, granulocytes and lymphocytes (Waksman, 1959; Johnson, 1970; Tung et al., 1970).

The principal reaction of the Sertoli cells appears to be phagocytosis of germ cells, especially late spermatids, in affected tubules. In severely affected tubules, elimination of spermatogenic cells is more or less complete; presumably Sertoli cells are responsible for disposing of cellular debris as degeneration spreads to cells at earlier stages of spermatogenesis.

Despite the correlation between inbreeding and susceptibility to orchitis in dogs (Fritz et al., 1976) and $t^{\mathrm{w} 18}$-bearing mice, the genetic bases for these phenomena remain to be determined. The most consistent abnormality observed in backcross $T / t^{\mathbf{w 1 8}}$ mice is sterility; orchitis appears sporadically in sexually mature males. Because of the nature of the breeding conditions by which these mice are generated, the sterility must be a consequence of genetic factors located on chromosome 17. However, it cannot simply be a result of the interaction of $T$ and $t^{\mathrm{w18}}$ because non-backcrossed $T / t^{\mathrm{w1} 18}$ males are fertile. Clearly other genetic factors must be involved. Furthermore, since sterility is also seen in female $T / t^{\mathrm{w18}}$ mice in this backcross, the genetic effect is not limited to spermatogenesis. 
Spermatogenic cells from sterile $t^{\mathbf{w 1 8}}$-bearing mice induce proliferation of syngeneic lymphocytes in vitro in contrast to spermatogenic cells from fertile mice that inhibit proliferation under the same conditions. In a previous study we provided evidence that spermatogenic cells from normal mice activate $\mathrm{T}$ lymphocytes in vitro which are responsible for suppressing the proliferation of lymphocytes despite the autoantigenicity of the spermatogenic cells (Hurtenbach et al., 1980). This suppression initiated by the germ cells was observed in allogeneic mixed lymphocyte cultures as well. The present results suggest that spermatogenic cells from young (6-10 weeks of age) but sexually mature $T / t^{\mathrm{w18}}$ males have the suppressive capacity of normal germ cells. However, this capacity is not retained normally, and loss of the ability to activate suppressor $\mathrm{T}$ lymphocytes in vitro appears to develop within the population of spermatogenic cells during reproductive life; this change correlates with the appearance of frank evidence of orchitis. The sporadic occurrence of the disease state and the fact that it is confined to individuals of mid-to-late reproductive age suggest that orchitis arises in this stock as an occasional consequence of chronic antigenic challenge to the animal's immune system without normal suppressive capability from cells of the male germ line. Consistent with this interpretation, we have also provided evidence that lymphocytes from sterile $T / t^{\mathbf{w 1 8}}$ males retain normal in-vitro responsiveness to syngeneic or allogeneic stimulator cells; these observations support our view that failure to maintain immunological tolerance in vivo is a property of the defective germ cells.

We thank Ms Joyce Dieckmann, Ms Florence Morgenstern and Ms Ludmilla Bardina for excellent technical assistance. This work was supported on NIH grant No. R01 HD-10669-04 and NSF grant No. PCM-77-17835. U.H. was supported by the Deutsche Forschungsgemeinschaft, Federal Republic of Germany.

\section{References}

Dooher, G.B. \& Bennett, D. (1973) Fine structural observations on the development of the sperm head in the mouse. Am. J. Anat. 136, 339-362.

Dym, M. Fawcett, D.W. (1970) Observations on the blood-testis barrier and on physiological compartmentation of the seminiferous epithelium. Biol. Reprod. 3, 308-326.

Fritz, T.E., Lombard, L.S., Tyler, S.A. \& Norris, W.P. (1976) Pathology and familial incidence of orchitis and its relation to thyroiditis in a closed beagle colony. Exp. mol. Pathol. 24, 142-158.

Hurtenbach, U., Morgenstern, F. \& Bennett, D. (1980) Induction of tolerance in vitro by autologous murine testicular cells. J. exp. Med. 151, 827-838.

Johnson, M.H. (1970) Changes in the blood-testis barrier of the guinea-pig in relation to histological damage following isoimmunization with testis. J. Reprod. Fert. 22, 119-127.

Johnson, M.H. (1973) Physiological mechanisms for the immunological isolation of spermatozoa. $A d v$. Reprod. Physiol. 6, 279-324.

Koo, G.C., Boyse, E.A. \& Wachtel, S.S. (1977) Immunogenetic techniques and approaches in the study of sperm and testicular cell surface antigens. In Immunobiology of Gametes, pp. 73-84. Eds $M$. Edidin \& M. H. Johnson. Cambridge University Press.

Tung, K.S.K. (1977) The nature of antigens and pathogenetic mechanisms in autoimmunity to sperm. In Immunobiology of Gametes, pp. 157-186. Eds M. Edidin \& M. H. Johnson. Cambridge University Press.

Tung, K.S.K. (1980) Autoimmunity of the testis- In Immunological Aspects of Infertility and Fertility Regulation, pp. 33-92. Eds D. S. Dhindsa \& G. F. B. Schumacher. North Holland, New York.

Tung, K.S.K., Unanue, E.R. \& Dixon, F.J. (1970) The immunopathology of experimental allergic orchitis. Am. J. Pathol. 60, 313-324.

Tung, K.S.K., Unanue, E.R. \& Dixon, F.J. (1971) Pathogenesis of experimental allergic orchitis. I. Transfer with immune lymph node cells. J. Immunol. 106, 1453-1472.

Waksman, B.H. (1959) A histological study of the auto-allergic testis lesion in the guinea pig. J. exp. Med. 109, 311-324. 